\title{
0 teatro no reino das virtudes
}

\section{Miguel Falcão}

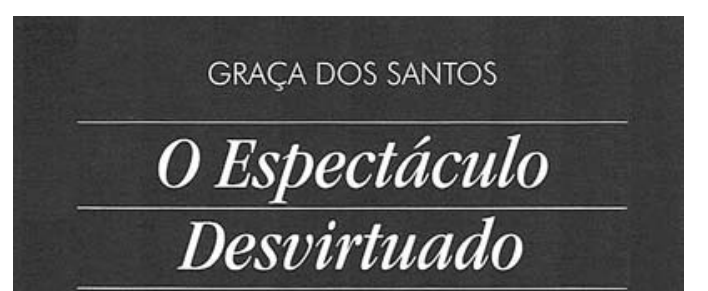

O teatro português sob o reinado de Salazar (1933-1968)

CAMINHO

colecção universitária

Num artigo, profundamente crítico, escrito para o Corriere della Sera (Março de 1960), Indro Mortanelli - citado por um biógrafo de Salazar, que procurava rebater a comparação - previa para o estadista português o mesmo que acontecera a Aristóteles: a condenação "ao ostracismo por ódio às suas virtudes"(D'Assac 1989: 245). Sem pretender avaliar aqui o seu rigor em relação ao filósofo grego, este enunciado adquire expressão pelo facto de, às portas da guerra colonial e sob forte pressão internacional, ter tido a ousadia de escarafunchar, embora à distância, no virtuoso reino do "chefe" português. É um exemplo, entre tantos, das vozes que se levantaram contra o "reduto" construído à imagem da sua concepção de "moralidade", assente, como muito bem se observa nesta obra, em princípios católicos, autoritários e corporativos, e suportada por uma estrutura civil, militar e religiosa, composta por uma "base de criaturas fiéis, seguras e a toda a hora manipuláveis" (p. 44). Rostos de um mesmo "corpo", desvendados nestas páginas.

Ainda antes de o professor universitário de economia política se ter tornado Ministro das Finanças do Presidente Carmona (1928), já António Ferro dera nas vistas, sobretudo ao lado de Almada, Pessoa, Sá Carneiro ou Santa Rita Pintor, como editor acidental da efémera revista Orpheu (1915) ou irreverente autor da proibida peça Mar alto
Graça dos Santos, $O$ espectáculo desvirtuado: $O$ teatro português sob o reinado de Salazar (1933-1968), trad. Lígia Calapez, Lisboa, Caminho, 2004, 386 pp.

(1922). Mas foi o jornalista cosmopolita que seduziu o ditador em potência, acabado de nomear para a liderança do governo, ao fazer-Ihe uma série de entrevistas, reunidas depois num volume (1932), a que, estrategicamente, vinculou um prefácio de Paul Valéry (de quem, aliás, repescara, desenvolvendo-a, a ideia de "Política do Espirito", que cativou Salazar). Paralelamente, nos jornais, foi escrevendo que fazia falta a Portugal um metteuren-scène que libertasse o pais da "letargia", que soubesse o que o povo desejava, mas ensinando-Ihe o que o regime queria, sem descurar as "vantagens da estetização da política" e da "propaganda através da arte" (p. 97).

Ferro surgiu a Salazar como a figura certa para preencher de conteúdo "intelectual" as prioridades estabelecidas pelo regime, como o rigor orçamental, a disciplina no trabalho ou o regresso à terra, sob a ordem "Deus, Pátria, Família". Salazar na cadeira, Ferro no Secretariado de Propaganda Nacional (SPN), eufemisticamente rebaptizado, após a Segunda Guerra, de Secretariado Nacional de Informação (SNI). Salazar era o homem da "véspera", guardião dos valores do passado e da tradição, que, até no teatro, preferia os ensaios gerais às estreias (p. 106), razão por que nunca foi visto no teatro (p. 53), precisamente para evitar o povo, o contacto, a partilha de emoções; Ferro era o "futurista", crítico de arte, poeta, cronista e conferencista, que tanto citava Mussolini como Oscar Wilde, e até experimentara ser actor ao lado da consagrada Lucilia Simões. Salazar, o mitificado, a sombra nos silêncios e nas ausências; Ferro, o popularizado, a voz dos discursos e a presença nos actos. A Salazar cabia a resolução dos "problemas essenciais" e a Ferro o "convívio mundano" (p. 104).

Foi neste molde de "flagrantes contrastes", entre o "seco e nodoso" Salazar e o "redondo e cheio" Ferro (p. 103) - o "duo harmonioso" (p. 100) -, que o Estado Novo e a respectiva imagem foram sendo erigidos. Por essa razão, a autora dedica-Ihes, com toda a pertinência e de forma desenvolvida, os dois primeiros capítulos do livro, "Salazar e o Salazarismo: Modelos obrigatórios" (pp. 43-79) e "António Ferro: entre Goebbels e Malraux" (pp. 81-148), procurando estabelecer conexões entre os seus percursos de vida e o exercício de altas funções ao serviço do regime, bem como com as respectivas repercussões em décadas da História de um país e de um povo. 
Espectadores do Teatro do Povo em Vila Nova da Baronia, 1940 (Museu Nacional do Teatro).

Espectadores do Teatro do Povo em Faro, 1956 (Museu Nacional do Teatro).

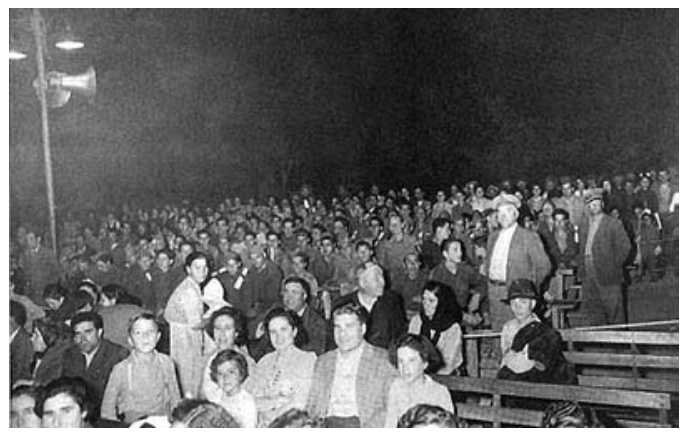

Ao longo da obra, é perceptivel a ênfase dada a três datas, que, para além de estabelecerem, no plano histórico, elos entre Ferro e o teatro, sinalizam, simbolicamente, as suas fases de afirmação/reconhecimento intelectual e artístico, de assunção/ascensão no poder e de afastamento/esquecimento em ambiente de certo aproveitamento oportunista. Entre 1925, ano em que estreou Knock de Jules Romain no inovador Teatro Novo, inaugurado com pretensas (/pretensiosas) analogias com o Vieux Colombier de Copeau, e 1936, ano da criação do Teatro do Povo, situam-se todas as diferenças. Até às entrevistas a Salazar, ainda lamentava a inexistência de um "teatro de vanguarda" ou de um "teatro de arte" e reclamava a não atribuição, pelo Estado, de subsidios ao teatro (pp. 100-101). Já director do SPN/SNI, empreendeu a "Política do Espírito", aceitando (e promovendo) a intromissão do Estado na indispensável autonomia da criação artística, com o intuito de transformar a arte - e designadamente o teatro - num "instrumento de propaganda encarregado de glorificar os valores promovidos pelo Estado" e de os injectar na sociedade "através da sua popularização forçada" (p. 65). Destinadas, ora ao Povo, ora aos Intelectuais e às "elites", sobretudo em Portugal, mas nalguns casos também no estrangeiro, sucederamse as "anestesias" resultantes da falsificação da "consciência histórica ideologicamente decalcada sobre o regime" (p. 66): colecções de literatura "laudatória", bibliotecas e cinemas itinerantes, prémios e concursos (também para teatro), arquitectura e escultura confinadas à função decorativa e de "fachada" do regime, "folclorizações" da arte (tendo o Verde Gaio, o "bailado russo português", como cartão de visita), a "aldeia mais portuguesa de Portugal", e, entre muitas outras promoções, festas, desfiles e comemorações, de que a Exposição do Mundo Português (1940) constituiu um dos momentos áureos, exaltando, em plena guerra mundial e perante um país mergulhado em miséria e repressão, as glórias de um passado feito mito. A terceira data - 1958, dois anos após a morte de Ferro - é referente à (re)proibição

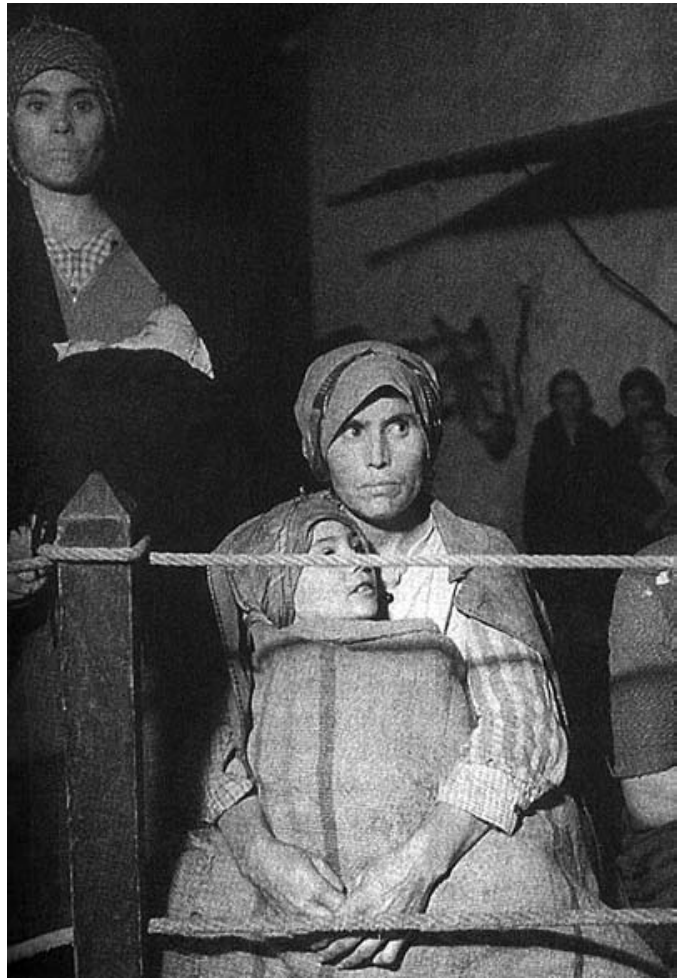

da representação de Mar alto, dado revelador do incómodo que a irreverência da sua juventude continuava a significar para o Estado Novo e, simultaneamente, do aproveitamento que o regime ainda pretendia fazer da sua obra.

A autora elege o Teatro do Povo - a que dedica o terceiro capítulo, subtitulado "uma criação do Poder" (pp. 149-219), e vários dos Anexos (pp. 358-362) - como itinerário principal para uma viagem por mais de duas décadas de espectáculo em Portugal, marcadas, no essencial, por dois períodos distintos, que a própria estruturação e programação da companhia reflectem: o teatro como assumido instrumento de propaganda ideológica até ao início dos anos 50, a que se segue um tempo em que se vislumbram "esboços de uma política de teatro" (p. 79).

Apesar das referências a Louis Jouvet e Gaston Baty no discurso de inauguração e de a própria designação fazer lembrar o Théâtre du Peuple, de Bussang, as motivações de Ferro e o objectivo deste "teatro itinerante" português estavam longe daquele projecto francês de "cidadania" que, sob o forte impulso de, entre outros, Maurice Pottecher, Romain Rolland, Firmin Gémier e mais tarde o Cartel des Quatre, lançaria as bases de um verdadeiro teatro popular e da descentralização teatral, que vieram a determinar o panorama cultural de todo o século. Entre 1936 e 1952, os programas dos espectáculos mantiveram-se inalterados: abriam sempre com a leitura de excertos do discurso inaugural de Ferro, a que se seguia o resumo e, finalmente, a representação de (por norma) duas peças, eivadas em geral, de acordo com o citado Luiz Francisco Rebello, de "moralismo primário", de "folclorismo anódino" ou de "didactismo político de baixo nivel" (p. 173). Quase tudo isto foi posto de parte na fase seguinte da companhia, que se "intelectualizou" para corresponder à onda, que alastrava pela Europa do pós-guerra, de interesse pelo "teatro popular", já com influência do Teatro Nacional Popular de Jean Vilar e da Volksbühne alemã, acabando por ser extinta em 1955 e substituida pelo Teatro da 


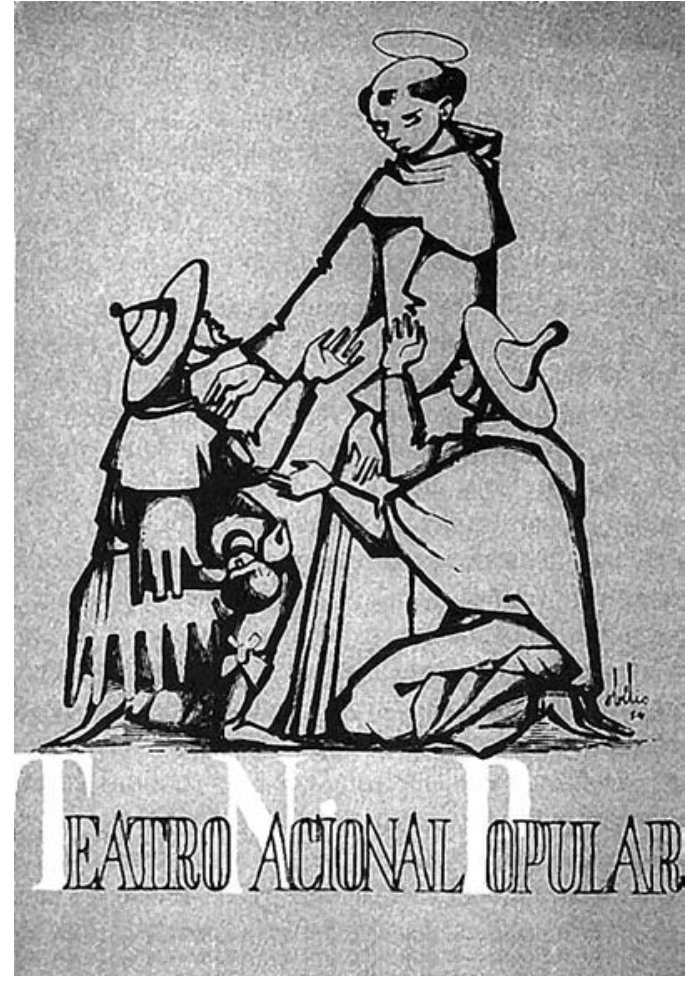

Campanha, novamente instrumento ideológico do regime. Instalado no Teatro da Trindade, o Teatro Nacional Popular na sua versão lusa (declaradamente inspirado no TNP de Vilar), fundado por Ribeirinho com actores do extinto Teatro do Povo, viria a apresentar, em Lisboa e em digressões, o repertório mais "revolucionário" até então apresentado nos palcos portugueses (p. 216), cujo auge foi atingido em 1959, com $\dot{A}$ espera de Godot, de Beckett.

No quarto capitulo, a autora apresenta um quadro exaustivo de "Uma legislação constrangedora" (pp. 221280) e no capítulo seguinte, "Recuperar o tempo perdido: o teatro português de 1945 aos anos sessenta" (pp. 281328), passa em revista algumas das experiências mais relevantes do teatro português, que sempre renascia a cada sinal de fraqueza da censura, desde o Teatro Nacional e da Revista à Portuguesa ao movimento de teatro independente, passando pelo teatro universitário.

Este livro de Graça dos Santos, docente universitária radicada em França desde muito nova, é uma versão remodelada da sua tese de doutoramento em Ciências Humanas (especialidade de Artes do Espectáculo), defendida na Universidade de Paris $X_{1}$ e corresponde a um longo periodo de investigação sobre o tema, durante o qual publicou inúmeros artigos e escreveu os verbetes relativos ao teatro português para o prestigiado Dictionnaire Encyclopédique du Théâtre, coordenado por Michel Corvin. A edição portuguesa integra o prefácio que o teatrólogo francês Robert Abirached, também orientador da tese, escrevera para a edição francesa (CNRS, 2002), antecedido por um outro, expressamente escrito por Maria Helena Serôdio, docente da Faculdade de Letras da Universidade de Lisboa. A pertinência, o interesse e o rigor geral da obra não são prejudicados por algumas imprecisões, que, todavia, se registam para eventuais correcções: a referência equívoca ao "surgimento do Neo-Realismo em 1945" (pp. 127,

128n), quando por essa altura estaria já a meio de uma primeira fase (cf. Torres 1977)'; a descodificação da sigla
SPN por "Secretaria de Propaganda Nacional" (p. 48), que, apesar de posteriormente corrigida, terá induzido Abirached a associar António Ferro, em vez de "director", à função de "Secretário de Estado para a Propaganda" (p. 27); e a tradução literal, a partir da versão francesa, dos títulos de textos dramáticos e de espectáculos, que nem sempre têm correspondência com os títulos com que, efectivamente, foram apresentados (ou divulgados) em Portugal ${ }^{2}$.

À medida dos valores e da natureza da sua "espécie de reinado" (p. 41), Salazar - que "não podia gostar de teatro" (p. 38) - soube encontrar nesta expressão artística as virtudes, tão paradoxalmente silenciosas (/silenciadoras) como propagandisticas, que melhor serviam os seus propósitos, preferindo "a sombra à luz, os bastidores ao palco, a palavra escrita à palavra dita" (ibidem). Nesta obra de grande fôlego, profusamente documentada, Graça dos Santos não se limita a apresentar-nos um dos mais relevantes estudos da acção "desvirtuadora" do salazarismo sobre o teatro. Apesar de nos advertir para a necessidade de "outro livro que questionasse a vida teatral portuguesa a partir de 1968" (p. 22), ao confrontar-nos com realidades que parecem por vezes ficções e ao reclamar o papel interveniente do público e a relação privilegiada entre cena e plateia (desde logo através das epígrafes de Bernard Dort e de Fernando Amado), não deixa, indirectamente, de nos interpelar sobre o teatro a que, apesar da obscura herança legada ao regime democrático, temos querido e/ou conseguido chegar, tanto nos territórios da criação e da fruição, como nos da formação e da investigação.

\section{Referências bibliográficas}

D'ASSAC, Jacques Ploncard (1989), Salazar: A vida e a obra, Lisboa, Verbo. TORRES, Alexandre Pinheiro (1977), O movimento neo-realista em Portugal na sua primeira fase, Lisboa, Instituto de Cultura e Lingua Portuguesa, Biblioteca Breve.
Cartaz, desenhado por Abilio, 1954 (Museu Nacional do Teatro).

\section{Datam de meados da década de 30 as primeiras grandes iniciativas de \\ afirmação de um (disfarçado por força do regime censório) "realismo socialista", de que se destacam, em 1939, as célebres discussões sobre arte pela arte vs. arte social, protagonizadas por José Régio e Álvaro Cunhal. Note-se ainda que até 1945 Alves Redol publicara cinco romances (Gaibéus, de 1940, é considerado o momento fundador do movimento), e estreara-se como dramaturgo nesse mesmo ano com Maria} Emilia. Por outro lado, eram já conhecidos alguns dos romances mais emblemáticos dos primeiros anos daquele movimento (como Esteirose Casa na duna, respectivamente, de Soeiro Pereira Gomes e Carlos de Oliveira e datados 1941 e 1943), e tinham sido já publicados todos os volumes de poesia da primeira (e única) série do Novo cancioneiro (1941-1944)

${ }^{2}$ De entre os vários casos, indico, a título de exemplo: na área dos espectáculos levados à cena por companhias portuguesas, O pomar das cerejas (em vez de Acerejeira) de Tchekov, pelo Teatro Estúdio de

Lisboa, em 1965 (p. 309n) e Insulto ao público (em vez de UItraje ao público) de Peter Handke, pelo Grupo 4, em 1972 (p. 311n); na área dos textos, designadamente da criação dramática portuguesa, Cavalgada nas nuvens (e não Cavalgada de nuvens) de Carlos Selvagem (p. 189) e O Render dos heróis (e não A rendição dos heróis) de José Cardoso Pires (p. 307n). 